\title{
Characteristics of smokers who have never tried to quit: evidence from the British Opinions and Lifestyle Survey
}

Aarohi Sharma ${ }^{1}$ and Lisa Szatkowski ${ }^{2^{*}}$

\begin{abstract}
Background: An understanding of the characteristics of smokers who have never tried to quit may be useful to help identify and target these individuals and encourage them to attempt to give up smoking. Using national survey data we investigated variables associated with smokers reporting never having tried to quit.

Methods: Using data from the 2007 and 2009 UK Office for National Statistics Opinions and Lifestyle Survey we identified all self-reported current smokers aged $16+$. The primary outcome was response to the question 'have you ever tried to quit smoking?' Univariable and multivariable logistic regression quantified the association between this outcome and several potential explanatory variables, including age, sex, socioeconomic status, health status, smoking behaviour, and knowledge of the dangers of smoking.
\end{abstract}

Results: Desire to quit was the most significant independent predictor of whether a smoker reported never having tried to quit. Smokers who reported that their health was good or very good were more likely to report never having tried to quit than those whose health was fair, bad or very bad (OR 1.59, 95\% Cl 1.05-2.41). Smokers who reported that no family members, friends or colleagues had been trying to get them to quit smoking in the last year were more likely to report never having tried to quit than those who reported that someone was trying to persuade them (OR 1.57, 95\% Cl 1.09-2.28). Smokers who hadn't received any cessation advice from a health professional in the last five years which they considered to be helpful were also more likely to report never having tried to quit.

Conclusions: Smokers who do not want to quit, who are in good health, whose friends and family are not trying to get them to quit, and who do not report receiving helpful advice to quit from a health professional, are more likely to report never having tried to quit.

\section{Background}

Smoking remains a major burden on the health of individuals and populations, responsible for approximately 79,100 deaths in England in 2011 [1]. Though smoking prevalence has declined in Britain since the 1970s, there is evidence of a slowing in the rate of progress more recently [2]. The frequently-cited, though contentious, 'hardening hypothesis' has been proposed to explain this, suggesting that smokers who find it easiest to quit have

\footnotetext{
* Correspondence: lisa.szatkowski@nottingham.ac.uk

${ }^{2}$ Division of Epidemiology and Public Health, UK Centre for Tobacco and Alcohol Studies, University of Nottingham, Clinical Sciences Building, Nottingham City Hospital, NG5 1 PB Nottingham, UK

Full list of author information is available at the end of the article
}

already done so, leaving behind a group of continuing smokers who are resistant to quitting $[3,4]$.

Previous work has sought to understand the factors associated with making a quit attempt. A study carried out in the USA reported that smokers were more likely to attempt to quit if they smoked fewer cigarettes per day, started smoking at a later age, had already made an attempt at quitting, were less dependent on nicotine, were facing greater pressure to stop smoking and had an expectation that they would quit in the near future [5]. However, this study used data from employees at a cancer treatment and research centre whose behaviour, if influenced by their place of work, may not be representative of all smokers. In addition, since the publication of this study in 1991 public attitudes towards smoking have 
changed considerably and a raft of tobacco control measures has been introduced in an attempt to reduce smoking prevalence. The variables reported in this study as risk factors for not attempting to quit may no longer hold true in this changed environment. More recent data have highlighted intention to quit, longer duration of previous quit attempts, younger age, negative attitudes about smoking, and lower levels of nicotine dependence as significant predictors of reporting having tried to give up smoking within the past year [6]. Agreement with the statements 'I like being a smoker' and 'I enjoy smoking' were reported as independent predictors of failing to make a quit attempt in a six month prospective study [7]. In a second prospective study of smokers who were not interested in quitting at baseline, self-reported motivation and self-efficacy to quit significantly predicted making a quit attempt during the six month follow-up period [8]. Experiencing financial stress has also been reported to be significantly associated with not trying to quit smoking over a one year follow-up period [9]. A systematic review synthesising existing literature found that having made a previous quit attempt and being motivated and intending to stop were the most dominant factors associated with making a quit attempt. Having a negative opinion about smoking, being worried about the effects of smoking on health and quality of life, expecting health benefits from quitting, having a ban on smoking in the home, and being confident of success in quitting also showed significant associations with making a quit attempt in a number of the studies identified for inclusion in the review [10].

To our knowledge few data exist which quantify the proportion of smokers who have never tried to quit and describe their characteristics. An understanding of these characteristics may be useful to identify and target smokers who have never tried to quit and encourage them to try to give up smoking. Given that cessation is a dynamic process and that many smokers will make many failed quit attempts before finally succeeding [11], it is crucial to encourage an attempt at cessation in smokers who might otherwise not try, in order to increase the likelihood of ultimate success.

This study uses recent data from the British Opinions and Lifestyle Survey, a repeated cross-sectional national survey, to examine the association between multiple potential risk factors and whether a smoker reports never having tried to quit smoking.

\section{Methods}

\section{Data source}

The UK Office for National Statistics (ONS) Opinions and Lifestyle Survey (formerly known as the ONS Opinions Survey and the ONS Omnibus Survey) is a multipurpose, face-to-face, modular monthly survey of adults aged 16+ living in private households in Great Britain. Further details about the survey methodology are available elsewhere $[12,13]$. In two months in most years the survey has gathered information about respondents' smoking behaviour; this study combines data from the October and November 2007 and February and March 2009 surveys, the two most recent surveys for which data were available at the time of writing. Current smokers were identified as those who responded positively to the question 'do you smoke cigarettes at all nowadays', and smokers who reported never having tried to quit were defined as those who responded negatively to the question 'have you ever tried to quit smoking?'.

Guided by the questions asked in the Opinions and Lifestyle Survey, as well as existing literature, data on several variables potentially associated with reporting never having tried to quit were extracted, as shown in Table 1. These data included socio-demographic information (age, sex, NS-SEC social group [14], highest qualification attained, access to a car and household type); health data (self-rated health and self-reported presence of a longstanding illness, disability or infirmity); smoking behaviour (daily cigarette consumption, time between waking and smoking the first cigarette of the day, smoking rules in the home); and quitting behaviour (desire and intention to quit, persuasion by others to quit, receipt of advice to quit from a health care professional). Respondents' knowledge of the dangers of smoking was assessed by whether they correctly identified smoking as the cause of most deaths before the age of 65 in the UK, from a range of possible answers including road accidents, accidents at work, AIDS, murder and manslaughter, illicit drugs and alcohol misuse. Knowledge of the dangers of passive smoking was quantified using responses to 12 questions which asked respondents whether living with a smoker and breathing someone else's smoke increases children's and non-smokers' risks of developing a number of conditions (such as asthma, ear infections, diabetes, cot death, chest infection lung cancer and heart disease). The number of correct responses each participant gave was calculated, and the variable cut at the median total score to give a binary variable indicating knowledge above and below the sample median.

All data were obtained from the UK Data Service [13], and no additional ethical approval was required for their use.

\section{Statistical analysis}

All analyses were carried out using STATA 12.0 (STATA Corp, College Station, TX). The Opinions and Lifestyle Survey uses a complex sampling methodology in which households are randomly selected from across the UK and then one person is randomly selected from each household for interview. A weighting variable is provided with 
Table 1 Univariable odds ratios for the association between risk factors and reporting never having tried to quit smoking

\begin{tabular}{|c|c|c|c|c|}
\hline Variable & $\mathbf{N}$ & $\%$ never tried to quit & Odds ratio $(95 \% \mathrm{Cl})$ & Wald p-value \\
\hline All respondents & 877 & 21.3 & & \\
\hline \multicolumn{5}{|l|}{ Sex } \\
\hline Female & 448 & 21.4 & 1.00 & \multirow{2}{*}{0.918} \\
\hline Male & 429 & 21.1 & $0.98(0.68-1.41)$ & \\
\hline \multicolumn{5}{|l|}{ Age group } \\
\hline $65+$ & 133 & 18.0 & 1.00 & \multirow{6}{*}{0.017} \\
\hline $55-64$ & 133 & 20.2 & $1.15(0.60-2.23)$ & \\
\hline $45-54$ & 158 & 13.9 & $0.74(0.37-1.47)$ & \\
\hline $35-44$ & 181 & 20.3 & $1.16(0.64-2.10)$ & \\
\hline 25-34 & 168 & 21.4 & $1.24(0.67-2.29)$ & \\
\hline $16-24$ & 104 & 35.1 & $2.47(1.30-4.67)$ & \\
\hline \multicolumn{5}{|l|}{ NS-SEC social group } \\
\hline Managerial and professional occupations & 226 & 16.8 & 1.00 & \multirow{4}{*}{0.080} \\
\hline Intermediate occupations & 157 & 20.4 & $1.27(0.72-2.26)$ & \\
\hline Routine and manual occupations & 431 & 21.8 & $1.39(0.89-2.17)$ & \\
\hline Not classified & 63 & 33.7 & $2.52(1.24-5.10)$ & \\
\hline \multicolumn{5}{|l|}{ Highest educational qualification } \\
\hline No formal qualifications & 290 & 23.4 & 1.00 & \multirow{6}{*}{0.087} \\
\hline Level 1 GCSE D-G & 54 & 20.6 & $0.85(0.41-1.78)$ & \\
\hline Level 2 GCSE $A^{*}-C$ & 186 & 16.5 & $0.65(0.38-1.10)$ & \\
\hline Level 3 A levels or equivalent & 110 & 31.5 & $1.50(0.87-2.59)$ & \\
\hline Level 4 At least some higher education & 148 & 18.3 & $0.73(0.41-1.32)$ & \\
\hline Other qualifications & 89 & 16.3 & $0.64(0.33-1.23)$ & \\
\hline \multicolumn{5}{|l|}{ Does your household have access to a car? } \\
\hline Has access to a car & 569 & 19.7 & 1.00 & \multirow{2}{*}{0.109} \\
\hline No access to a car & 308 & 25.1 & $1.37(0.93-2.00)$ & \\
\hline \multicolumn{5}{|l|}{ Household structure } \\
\hline One person only & 294 & 22.9 & 1.00 & \multirow{6}{*}{0.079} \\
\hline Married cohabiting with dependent child & 164 & 21.9 & $0.95(0.58-1.54)$ & \\
\hline Married cohabiting no dependent child & 243 & 15.9 & $0.64(0.40-1.00)$ & \\
\hline Lone parent with dependent child & 100 & 22.9 & $1.00(0.53-1.88)$ & \\
\hline Lone parent no dependent child & 18 & 16.8 & $0.68(0.18-2.49)$ & \\
\hline Other & 58 & 34.7 & $1.79(0.94-3.40)$ & \\
\hline \multicolumn{5}{|l|}{ How good is your health? } \\
\hline Fair/bad/very bad & 272 & 15.0 & 1.00 & \multirow{2}{*}{0.007} \\
\hline Good/very good & 605 & 23.7 & $1.76(1.16-2.67)$ & \\
\hline \multicolumn{5}{|l|}{ Do you have a longstanding illness? } \\
\hline Yes, and limits activities & 220 & 17.3 & 1.00 & \multirow{3}{*}{$0.040^{*}$} \\
\hline Yes, but does not limit activities & 93 & 13.1 & $0.72(0.33-1.58)$ & \\
\hline Do not have illness/disability & 564 & 24.0 & $1.51(0.96-2.36)$ & \\
\hline \multicolumn{5}{|l|}{ Average daily cigarette consumption } \\
\hline 10 or less & 84 & 23.0 & 1.00 & \multirow{2}{*}{0.712} \\
\hline 11 to 20 & 91 & 25.9 & $1.17(0.53-2.58)$ & \\
\hline
\end{tabular}


Table 1 Univariable odds ratios for the association between risk factors and reporting never having tried to quit smoking (Continued)

\begin{tabular}{llll}
\hline 21 to 30 & 214 & 21.5 & $0.92(0.47-1.78)$ \\
$31+$ & 488 & 19.9 & $0.83(0.45-1.53)$
\end{tabular}

How soon after waking do you smoke your first cigarette of the day?

$\begin{array}{llll}\text { After } 60 \text { minutes } & 318 & 24.1 & 1.00 \\ 30-59 \text { minutes } & 171 & 17.3 & 0.66(0.39-1.10) \\ 5 \text { - } 29 \text { minutes } & 261 & 22.4 & 0.91(0.59-1.40) \\ \text { Within } 5 \text { minutes } & 127 & 16.2 & 0.61(0.32-1.14)\end{array}$

Which statement best describes the rules on smoking inside your home?

\begin{tabular}{|c|c|c|c|}
\hline Smoking is not allowed at all & 218 & 19.5 & 1.00 \\
\hline Smoking is allowed in some rooms or at some times & 395 & 18.2 & $0.92(0.58-1.46)$ \\
\hline Smoking is allowed anywhere & 264 & 28.2 & $1.62(1.00-2.62)$ \\
\hline \multicolumn{4}{|l|}{ How much do you want to quit? } \\
\hline Very much indeed & 218 & 6.69 & 1.00 \\
\hline Quite a lot & 209 & 15.5 & $2.56(1.20-5.47)$ \\
\hline A Fair amount & 129 & 20.2 & $3.52(1.59-7.79)$ \\
\hline A little & 67 & 21.0 & $3.71(1.53-8.97)$ \\
\hline Don't want to quit & 254 & 38.7 & $8.82(4.44-17.51)$ \\
\hline \multicolumn{4}{|l|}{ When do you intend to give up smoking? } \\
\hline Within the next month & 117 & 12.3 & 1.00 \\
\hline Within the next 6 months & 201 & 10.8 & $0.86(0.39-1.92)$ \\
\hline Within the next year & 157 & 11.2 & $0.90(0.39-2.09)$ \\
\hline Some point after next year & 156 & 23.3 & $2.16(1.02-4.59)$ \\
\hline I have no intention of giving up & 246 & 39.8 & $4.72(2.38-9.35)$ \\
\hline
\end{tabular}

During the last year has a family member, friend or colleague been trying to get you to quit smoking?

$\begin{array}{lllll}\text { Yes } & 469 & 15.2 & 1.00 & <0.001 \\ \text { No } & 408 & 28.8 & 2.25(1.54-3.28)\end{array}$

In the last 5 years have you been given advice on smoking by a health professional and did you find it helpful?

$\begin{array}{lccc}\text { Yes, I had a helpful discussion } & 266 & 10.1 & 1.00 \\ \text { Yes, I was given something helpful to take away and read } & 44 & 14.5 & 1.51(0.50-4.51) \\ \text { Yes, I had a discussion but didn't find it useful } & 143 & 25.3 & 3.02(1.59-5.74) \\ \text { Yes, I was given something to take away and read but didn't find it useful } & 65 & 23.3 & 2.70(1.23-5.94) \\ \text { No, I didn't receive any advice } & 359 & 28.6 & 3.57(2.09-6.11)\end{array}$

Did the respondent identify smoking as the cause of most deaths before the age of 65 in the UK?

$\begin{array}{ll}\text { Yes, correct response given } & 330 \\ \text { No, incorrect response given } & 547\end{array}$

$330 \quad 17.3$

$547 \quad 23.6$

1.00

$1.48(1.01-2.17)$

0.046

How good is your knowledge about the dangers of passive smoking?

Above average

Below average

$\begin{array}{lll}506 & 18.9 & 1.00 \\ 371 & 24.5 & 1.39(0.96-2.00)\end{array}$

0.079

$\mathrm{OR}=$ odds ratio, $95 \% \mathrm{Cl}=95 \%$ confidence interval.

*Adjusted Wald p-values accounting for survey design may appear significant event though the confidence intervals for each category do not.

the dataset which corrects for the unequal probability of selection, and we used Stata's survey commands to account for this survey design in all analyses. Initially, univariable logistic regression was used to investigate the unadjusted association between each explanatory variable and whether smokers reported never having tried to quit. All variables deemed significant risk factors in the univariable analysis were initially included in a multivariable 
model. We then used non-automated backwards stepwise procedures with a cut-off $\mathrm{p}$ value of 0.05 to build a parsimonious adjusted model, with adjusted Wald probability values (compatible with Stata's survey commands) used to determine the significance of each variable in the final model. We examined the variance inflation factor to check for collinearity between variables included in the final multivariable model.

\section{Results}

From the combined survey response of 4,413 interviews in 2007 and 2009, 948 respondents reported smoking (20.8\% accounting for survey design, 95\% CI 19.5-22.1). One respondent did not state whether they had ever tried to quit, giving useable data from 947 people. 70 respondents (7.4\%) did not have data available for one or more variables and so these people were excluded from analysis, leaving a sample of 877 current smokers with answers available across all potential explanatory variables. As a sensitivity analysis we compared our results from this complete case analysis with those from models in which missing data for each categorical variable were coded as a separate category; the results did not differ and so for brevity we present only the results from the complete case analysis here.

Our final sample consisted of 877 current smokers, of whom 184 (21.3\%, 95\% CI 18.4-21.5) reported that they had never tried to give up smoking. Table 1 shows the univariable association between each of the potential explanatory variables and the outcome of reporting never having tried to quit smoking.

As Table 1 indicates, several variables showed a statistically significant univariable association with reporting never having tried to quit smoking. Younger smokers were more likely to report they have never tried to quit, as were smokers in good or very good health. Respondents living in houses where smoking was allowed anywhere were more likely to report not having tried to quit compared to those living in houses where smoking was not allowed at all. Reporting not having tried to quit was also more likely amongst smokers who do not want to quit, had no intention of giving up or of giving up in the next year, and where nobody had been trying to get them to give up. Smokers who haven't received any cessation advice from a health professional in the last five years, and those who did not find any advice or leaflets they were given to be useful, were approximately three times more likely to report not having tried to quit than those who reported receiving a helpful intervention.

Table 2 shows the full multivariable model indicating the variables which were independent risk factors for reporting never having tried to quit smoking. There was strong collinearity between respondents' self-rated health and reported presence of a longstanding illness, but only the former was significant in the final multivariable model. Examination of the variance inflation factor suggested no collinearity between any variables included in the final model.

In the multivariable model, desire to quit was the most significant independent predictor of whether a smoker reports never having tried to quit. Smokers who reported that their health was good or very good were more likely to report never having tried to quit than those whose health was fair, bad or very bad (OR 1.59, 95\% CI 1.05-2.41). Smokers who reported that no family members, friends or colleagues had been trying to get them to quit smoking in the last year were also more likely to report not having tried to quit than those who reported that one of these had been trying to persuade them (OR 1.57, 95\% CI 1.09-2.28). Smokers who haven't received any cessation advice from a health professional in the last five years, and those who did not find any advice or leaflets they were given to be useful, were over twice as likely to report not having tried to quit than those who reported receiving a helpful intervention (thought the latter association was marginally non-statistically significant).

\section{Discussion}

This study has highlighted four independent risk factors for smokers reporting never having tried to quit - selfreported health, desire to quit, the influence of other people in trying to prompt a cessation attempt, and whether cessation support perceived to be useful was received from a health professional.

Motivation to quit smoking is already known to be a significant risk factor influencing the chances of making a cessation attempt $[11,15]$ and therefore it is unsurprising that a lack of desire to quit results here in an increase in the odds ratio for reporting never having made a cessation attempt. Similarly, it is unsurprising that smokers who reported their health to be good or very good were more likely to report never having tried to quit. The presence of health problems, particularly those directly attributable to smoking, is known to be a feature which prompts many smokers to evaluate their smoking behaviour and consider trying to quit [16].

This study highlights the important role that other people can play in ensuring a smoker tries to quit, be they healthcare professionals or friends and family members. Existing studies have shown that smokers who report being under pressure to stop are more likely to report making a quit attempt [5], and the results present here corroborate the opposite, that smokers who report that no one is encouraging them to stop are less likely to have tried to quit. Smokers cite receiving cessation advice from a physician as an important factor which can motivate them to quit [17]. Systematic review evidence 
Table 2 Multivariable odds ratios for the association between risk factors and reporting never having tried to quit smoking

\begin{tabular}{ll}
\hline Variable & Adjusted OR (95\% Cl) \\
\hline How good is your health? & 1.00 \\
Fair/bad/very bad & $1.59(1.05-2.41)$ \\
Good/very good & \\
How much do you want to quit? & 1.00 \\
Very much indeed & $2.25(1.15-4.40)$ \\
Quite a lot & $3.16(1.56-6.40)$ \\
A Fair amount & $3.31(1.49-7.36)$ \\
A little & $6.97(3.77-12.87)$ \\
Don't want to quit & 1.00 \\
During the last year has a family member, friend or colleague been trying to get you to quit smoking? \\
Yes & $1.57(1.09-2.28)$ \\
No & $<.027$ \\
In the last 5 years have you been given advice on smoking by a health professional and did you find it helpful? \\
Yes, I had a helpful discussion & 1.00 \\
Yes, I was given something helpful to take away and read & $1.26(0.46-3.41)$ \\
Yes, I had a discussion but didn't find it useful & $2.59(1.42-4.71)$ \\
Yes, I was given something to take away and read but didn't find it useful & $2.10(0.98-4.51)$ \\
No, I didn't receive any advice & $2.69(1.60-4.52)$ \\
\hline
\end{tabular}

$\mathrm{OR}=$ odds ratio, $95 \% \mathrm{Cl}=95 \%$ confidence interval; ORs are mutually adjusted for the other variables included in the table.

suggests that six month quit rates among smokers who receive advice are one to three percentage points higher than unassisted cessation rates [18]. The results presented here suggest that whether a smoker perceives an intervention by a physician to be helpful is also an important factor associated with whether they report never having tried to quit. Smokers who hadn't received any advice, or where their discussion with the healthcare professional or literature they were given were not perceived to be helpful, were over twice as likely to report never having tried to quit compared to those who reported a helpful discussion. There is some evidence that a helpful discussion with a healthcare professional is more strongly associated with making a quit attempt than the provision of literature to take away and read, even if the latter is also perceived as helpful. These results suggest that healthcare professionals should strive to deliver cessation interventions in a way that smokers will perceive as helpful, and should endeavour to check that the patient has understood the cessation message being conveyed to them.

As with all cross-sectional studies using survey data, this work has limitations. Data may be subject to recall and response biases and it is impossible to confirm the temporality of the association between risk factors and selfreported quit attempts. In addition, we acknowledge that many smokers may forget, and fail to report, quit attempts, particularly if the attempt was of short duration or was made a long time previously [19-21]. Despite these limitations, this study provides the most up-to-date information available about the characteristics of smokers who report never having tried to quit.

\section{Conclusion}

Our results suggest a need to ensure cessation messages resonate with those smokers who are most likely to report never having tried to quit - the healthy, those who don't want to give up smoking, and those who are not being encouraged to quit by other people. Healthcare professionals should be encouraged to deliver cessation support at every available opportunity. Further research is warranted to understand the appropriateness, feasibility and effectiveness of different ways of motivating the friends and families of smokers to encourage and support their loved ones to quit.

\section{Competing interests}

The authors declared that they have no competing interests.

\section{Authors' contributions}

LS conceived the study. AS and LS performed the statistical analysis. Both authors wrote the paper and have read and approved the final manuscript.

\section{Acknowledgements}

Lisa Szatkowski is a member of The UK Centre for Tobacco and Alcohol Studies. Funding to UKCTAS from the British Heart Foundation, Cancer Research UK, the Economic and Social Research Council, the Medical Research Council and the National Institute of Health Research, under the auspices of the UK Clinical Research Collaboration, is gratefully 
acknowledged. The authors thank Professor Ann McNeill, King's College London, for her comments on the manuscript.

\section{Author details}

'Division of Epidemiology and Public Health, University of Nottingham, Clinical Sciences Building, Nottingham City Hospital, NG5 1 PB Nottingham, UK. ${ }^{2}$ Division of Epidemiology and Public Health, UK Centre for Tobacco and Alcohol Studies, University of Nottingham, Clinical Sciences Building, Nottingham City Hospital, NG5 1 PB Nottingham, UK.

Received: 9 December 2013 Accepted: 7 April 2014 Published: 11 April 2014

\section{References}

1. The Information Centre: Statistics on Smoking: England, 2012. London: The Health and Social Care Information Centre; 2012.

2. Dunstan S: General Lifestyle Survey overview: A report on the 2010 General Lifestyle Survey. Office for National Statistics: Newport; 2012.

3. Warner KE, Burns DM: Hardening and the hard-core smoker: concepts, evidence, and implications. Nicotine Tob Res 2003, 5:37-48.

4. Docherty G, McNeill A: The hardening hypothesis: does it matter? Tob Control 2012, 21:267-268.

5. Hellman R, Cummings KM, Haughey BP, Zielezny MA, O'Shea RM: Predictors of attempting and succeeding at smoking cessation. Health Educ Res 1991, 6:77-86.

6. Hyland A, Borland R, Li Q, Yong HH, McNeill A, Fong GT, O'Connor RJ, Cummings KM: Individual-level predictors of cessation behaviours among participants in the International Tobacco Control (ITC) Four Country Survey. Tob Control 2006, 15(Suppl 3):iii83-iii94.

7. Tombor I, Shahab L, Brown J, West R: Positive smoker identity as a barrier to quitting smoking: findings from a national survey of smokers in England. Drug Alcohol Depend 2013, 133:740-745.

8. Jardin BF, Carpenter MJ: Predictors of quit attempts and abstinence among smokers not currently interested in quitting. Nicotine Tob Res 2012, 14:1197-1204.

9. Siahpush M, Yong H-H, Borland R, Reid $J$, Hammond D: Smokers with financial stress are more likely to want to quit but less likely to try or succeed: findings from the International Tobacco Control (ITC) Four Country Survey. Addiction 2009, 104:1382-1390.

10. Vangeli E, Stapleton J, Smit ES, Borland R, West R: Predictors of attempts to stop smoking and their success in adult general population samples: a systematic review. Addiction 2011, 106:2110-2121.

11. Zhou X, Nonnemaker J, Sherrill B, Gilsenan AW, Coste F, West R: Attempts to quit smoking and relapse: factors associated with success or failure from the ATTEMPT cohort study. Addict Behav 2009, 34:365-373.

12. Office for National Statistics: Opinions and Lifestyle Survey. http://www.ons. gov.uk/ons/about-ons/products-and-services/opn/index.html (accessed 3 December 2013).

13. UK Data Service: Opinions and Lifestyle Survey. http://discover.ukdataservice. ac.uk/series/?sn=2000043 (accessed 2 December 2013).

14. Office for National Statistics: The National Statistics Socio-economic Classification. http://www.ons.gov.uk/ons/guide-method/classifications/ current-standard-classifications/soc2010/soc2010-volume-3-ns-sec-rebasedon-soc2010-user-manual/index.html (accessed 6 August 2013).

15. Borland R, Yong H-H, Balmford J, Cooper J, Cummings KM, O'Connor RJ, McNeill A, Zanna MP, Fong GT: Motivational factors predict quit attempts but not maintenance of smoking cessation: Findings from the International Tobacco Control Four country project. Nicotine Tob Res 2010, 12:S4-S11.

16. Wilkes S, Evans A: A cross-sectional study comparing the motivation for smoking cessation in apparently healthy patients who smoke to those who smoke and have ischaemic heart disease, hypertension or diabetes. Fam Pract 1999, 16:608-610.

17. Ritvo PG, Irvine MJ, Lindsay EA, Kraetschmer N, Blair N, Shnek ZM: A critical review of research related to family physician-assisted smoking cessation interventions. Cancer Prev Control 1997, 1:289-303.

18. Stead LF, Bergson G, Lancaster T: Physician advice for smoking cessation. Cochrane Database Syst Rev 2008(Issue 2): . Art. No.:CD000165. doi:10.1002/ 14651858.CD000165.pub3.

19. Borland R, Partos TR, Yong HH, Cummings KM, Hyland A: How much unsuccessful quitting activity is going on among adult smokers? Data from the International Tobacco Control Four Country cohort survey. Addiction 2012, 107:673-682.

20. West R: Feasibility of a National Longitudinal Study (The Smoking Toolkit Study) to Monitor Smoking Cessation and Attempts at Harm Reduction in the UK. Pilot Report. http://www.smokinginengland.info/Ref/stp001.pdf (Archived byWebCite ${ }^{\odot}$ at http://www.webcitation.org/5zSCERpH2) (accessed 6 August 2013)

21. Berg CJ, An LC, Kirch M, Guo H, Thomas JL, Patten CA, Ahluwalia JS, West R: Failure to report attempts to quit smoking. Addict Behav 2010, 35:900-904.

doi:10.1186/1471-2458-14-346

Cite this article as: Sharma and Szatkowski: Characteristics of smokers who have never tried to quit: evidence from the British Opinions and Lifestyle Survey. BMC Public Health 2014 14:346.

\section{Submit your next manuscript to BioMed Central and take full advantage of:}

- Convenient online submission

- Thorough peer review

- No space constraints or color figure charges

- Immediate publication on acceptance

- Inclusion in PubMed, CAS, Scopus and Google Scholar

- Research which is freely available for redistribution 